\title{
New multi-model approach gives good estimations of wheat yield under semi-arid climate in Morocco
}

\author{
Simone Bregaglio • Nicolò Frasso • Valentina Pagani • Tommaso Stella • \\ Caterina Francone • Giovanni Cappelli • Marco Acutis • Riad Balaghi • \\ Hassan Ouabbou • Livia Paleari • Roberto Confalonieri
}

Accepted: 6 March 2014 / Published online: 4 April 2014

(C) INRA and Springer-Verlag France 2014

\begin{abstract}
Wheat production in Morocco is crucial for economy and food security. However, wheat production is difficult because the semi-arid climate causes very variable wheat yields. To solve this issue, we need better prediction of the impact of drought on wheat yields to adapt cropping management to the semi-arid climate. Here, we adapted the models WOFOST and CropSyst to agro-climatic conditions in Morocco. Six soft and durum wheat varieties were grown during the 2011-2012 and 2012-2013 growing seasons in the experimental sites of Sidi El Aydi, Khemis Zemamra and Marchouch. Drip irrigation and rainfed treatments were arranged in a randomised-block design with three replicates. We determined the phenological stages of emergence, tillering, stem elongation, flowering and maturity. We measured aboveground biomass six times along the season. These data were used to adapt WOFOST and CropSyst to local conditions. Our results show that both models achieved good estimations, with $R^{2}$ always higher than 0.91 , and positive values for Nash and Sutcliffe modelling efficiencies. Results of spatially distributed simulations were then analysed for the whole country in terms of different response to drought.
\end{abstract}

\footnotetext{
S. Bregaglio $(\bowtie) \cdot$ N. Frasso • V. Pagani $\cdot$ T. Stella $\cdot$ C. Francone $\cdot$ G. Cappelli $\cdot$ M. Acutis $\cdot$ L. Paleari $\cdot$ R. Confalonieri Department of Agricultural and Environmental Sciences Production, Landscape, Agroenergy, Cassandra lab, Università degli Studi di Milano, via Celoria 2, 20133 Milan, Italy

e-mail: simone.bregaglio@unimi.it

R. Balaghi

Department of Environment and Natural Resources, Institut National de la Recherche Agronomique, Avenue Hassan II, B.P. 415, Rabat, R.P., Morocco

H. Ouabbou

Department of Plant Breeding and Genetic Resources, Centre Régional de la Recherche Agronomique de Settat, Institut National de la Recherche Agronomique, B.P. 589, Settat, Morocco
}

Keywords Food security $\cdot$ Drought $\cdot$ Water stress $\cdot$ Crop monitoring $\cdot$ WOFOST $\cdot$ CropSyst

\section{Introduction}

Cereal production is responsible for about $15-20 \%$ of the Moroccan gross agricultural product, with direct repercussions on the employment levels in rural areas, on the food processing industry and - in light of the high per capita consumption-on food security issues (Balaghi et al. 2012). Although Morocco presents suboptimal agro-meteorological conditions for wheat growing (Mrabet 2000), this crop can be considered as a staple food in the country, with an average production of 4.2 million tonnes per year from 2000-2001 to 20112012 on 2.9 million-hectares harvested area, according to the official statistics of the Ministry of Agriculture. Both soft-Triticum aestivum L.-and durum-Triticum durum L.- wheats are cultivated in Morocco (Fig. 1) across the main six agro-ecological zones (Gommes et al. 2009), ranging from a typical Mediterranean climate in the northern coasts to continental conditions in the Central regions and in the mountainside areas in the West High Atlas, and to semi-arid environments in the southern part of the wheat-cropped area at the north of the Sahara (Confalonieri et al. 2013a). Soft wheat production is concentrated in the Atlantic plains of Morocco, from semi-arid to sub humid provinces, whereas durum wheat is mainly grown in the semi-arid south western plains (Balaghi et al. 2012).

The major constraint to wheat production all over Morocco is drought (Balaghi et al. 2008), which usually occurs in two main periods during the crop cycle: the first in the emergence and post-emergence phases and the second during grain filling, referred to as terminal drought, which directly affects 
Fig. 1 Field plots of durum wheat grown under drip irrigation system in Sidi El Aydi station

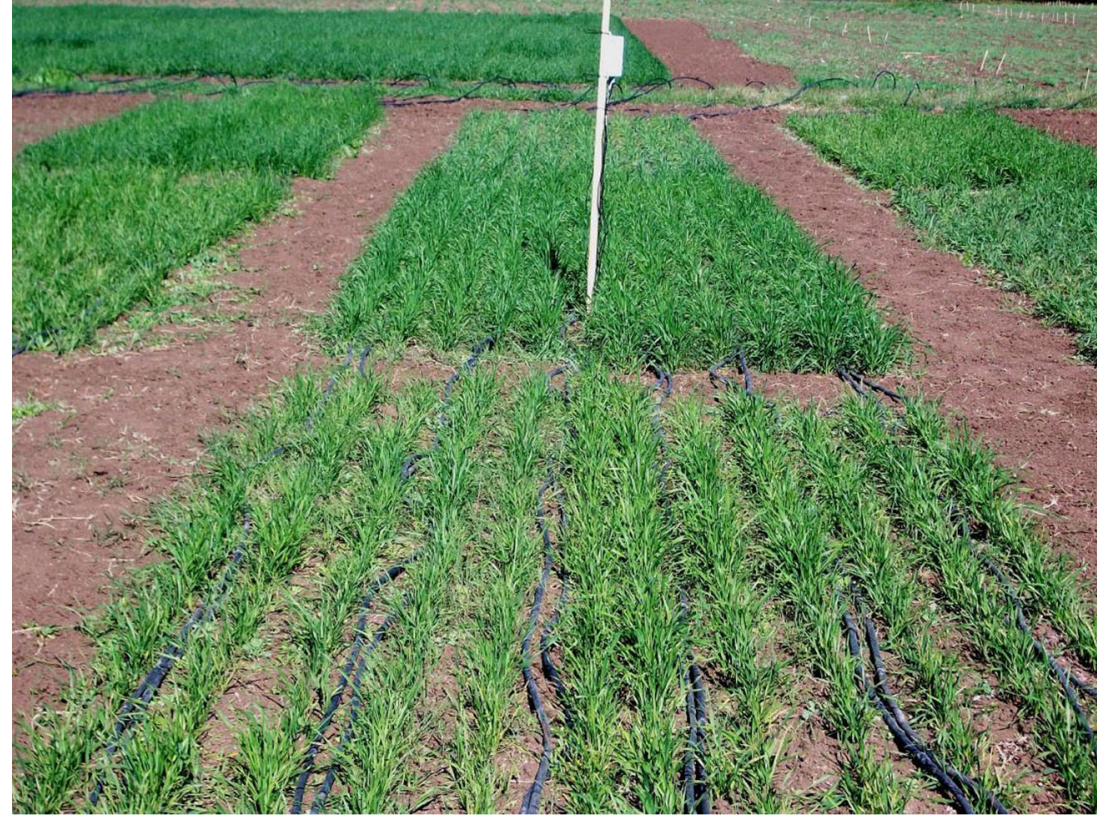

grains set (Karrou 1998). The impact of water stress on crop production is strongly influenced by its intensity and duration: it is estimated that yield can be reduced up to $25 \%$ when drought occurs at early stages, whereas such a gap can reach $85 \%$ in case a severe water stress affects the crop from emergence to flowering (INRA-Morocco 2002). Rainfall amount and distribution during the crop cycle are therefore crucial in determining wheat production in Morocco, which varied, e.g., from 1.1 million tonnes in the very dry cropping season of 1994-1995 to 5.9 in the subsequent and contrasting very wet season of 1995-1996. Other stressors in order of importance are the Hessian fly pest, Mayetiola destructor, (El Bouhssini et al. 2013) and the complex of fungal pathogens responsible for yellow and brown rusts, i.e. Puccinia striiformis and Puccinia recondita, other than Septoria tritici and Helmintosporium spp. (Bouftass et al. 2010).

The combination of the recurrent occurrence of drought and of the severe impact of biotic stressors reflects into marked season-to-season fluctuations in wheat yields at regional and national levels (Balaghi et al. 2008). This situation is made even more exacerbated by recent trends in international markets (Hertel et al. 2010) and by the negative impact of climate change on some of the most important wheat world producers (Porter and Semenov 2005), which are pushing Moroccan government towards the achievement of food security via the introduction of alternative agricultural practices such as minimum tillage or no-till system and of monitoring and forecasting tools (e.g., Balaghi et al. 2008). The availability of operational monitoring systems is crucial to provide objective, timely and quantitative yield forecasts at the regional and national scale, thus addressing the needs of multiple stakeholders involved at different levels in the agricultural sector.

Most of the existing crop yield forecasting systems have been developed by coupling a single generic or speciesspecific crop model with weather and soil databases in order to perform large-area simulations of crop growth and development under potential and, in some cases, water-limiting conditions (Duchemin et al. 2008), despite recent trends in crop modelling, e.g. the Agricultural Model Intercomparison and Improvement Project (www.agmip.org), are demonstrating how the adoption of a multi-model approach to yield prediction presents clear advantages compared to the use of a single crop simulator. This is because the available models present alternative formulations for the reproduction of the key biophysical processes involved in crop growth and development, with variable accuracy under different conditions of application (Asseng et al. 2013). Another limit of most of the available model based-yield forecasting systems is the rough adaptation to real contexts, which instead should envisage the calibration of model parameters with data from field experiments prior to applying them as forecasting tools. This is even more important when such monitoring and forecasting systems are transferred to developing countries which often face adverse weather conditions (Basso et al. 2013). In these contexts, indeed, the uncertainty in the available agrometeorological and pedological input data, combined with the difficulty in gathering high-quality calibration datasets may partially invalidate the usefulness of applying crop models for these purposes.

The activities performed during the project Crop Monitoring as an E-Agricultural Tool for Developing Countries, 
funded by the European Seventh Framework Programme, aimed to transfer the technology developed for the crop yield forecasting system of the European Commission to wheat in Morocco. The most challenging task was represented by the need of adapting the system to reproduce the specific growing conditions explored by wheat in semi-arid areas, with special attention to the issues related to the impact of drought on the inter-annual wheat yield fluctuations. The first step towards the fulfilling of this objective was the identification of the most relevant parameters of the models WOrld FOod STudies (WOFOST) (van Keulen and Wolf 1986) and CropSyst (Stöckle et al. 2003), via a multi-season, spatially distributed sensitivity analyses carried out on the whole Moroccan wheatcropped area (Confalonieri et al. 2013b).

The present study refers to the second step towards the realisation of a specific multi-model wheat forecasting system in the country. The two objectives were:

- To calibrate and evaluate the generic crop models WOFOST and CropSyst for reproducing drought impact on the growth and development of Moroccan soft and durum wheat varieties, using data collected in dedicated field experiments;

- To investigate the behaviour of the models when applied to the whole Moroccan wheat-cropped area in two seasons contrasting for rainfall, in order to analyse their responses to various degrees of drought.

\section{Materials and methods}

\subsection{Experimental data}

Data used for calibration and evaluation of WOFOST and CropSyst were collected from field experiments carried out in three experimental stations of the National Institute of Agronomic Research of Morocco: Sidi El Aydi, Khemis Zemamra and Marchouch (Table 1), during the two cropping seasons 2011-2012 and 2012-2013.

Marchouch is located in the favourable agro-ecological zone (Fig. 2), characterised by mild and long growing seasons and adequate rainfall volumes $\left(>400 \mathrm{~mm} \mathrm{season}^{-1}\right)$ and distribution, whereas Sidi El Aydi is located in the intermediate region, where growing seasons are shorter and rainfall amounts normally range from 300 to $400 \mathrm{~mm}$ season $^{-1}$. The Khemis Zemamra site belongs to the unfavourable south region, characterised by very short growing seasons and dry conditions, i.e. 200 to $300 \mathrm{~mm}^{\text {season }}{ }^{-1}$.

Table 1 Experimental data used to calibrate and evaluate the models used in this study

\begin{tabular}{|c|c|c|c|c|c|c|}
\hline Station & $\begin{array}{l}\text { Latitude N } \\
\text { Longitude W }\end{array}$ & Wheat type & Treatment & Cropping season & Cultivar & Sowing date \\
\hline \multirow[t]{12}{*}{ Sidi El Aydi } & \multirow{12}{*}{$\begin{array}{l}33.167 \\
7.400\end{array}$} & Durum & Irrigated & 2011-2012 & Marzak*, Karim*, Tarek & 30 Nov. \\
\hline & & Soft-low & Irrigated & 2011-2012 & Achtar*, Amal & 30 Nov. \\
\hline & & Soft-high & Irrigated & 2011-2012 & Arrihane* & 30 Nov. \\
\hline & & Durum & Rainfed & 2011-2012 & Marzak, Karim, Tarek & 30 Nov. \\
\hline & & Soft-low & Rainfed & 2011-2012 & Achtar, Amal & 30 Nov. \\
\hline & & Soft-high & Rainfed & 2011-2012 & Arrihane & 30 Nov. \\
\hline & & Durum & Irrigated & 2012-2013 & Marzak, Karim, Tarek* & 17 Nov. \\
\hline & & Soft-low & Irrigated & 2012-2013 & Achtar, Amal* & 17 Nov. \\
\hline & & Soft-high & Irrigated & 2012-2013 & Arrihane & 17 Nov. \\
\hline & & Durum & Rainfed & 2012-2013 & Marzak, Karim, Tarek & 17 Nov. \\
\hline & & Soft-low & Rainfed & 2012-2013 & Achtar, Amal & 17 Nov. \\
\hline & & Soft-high & Rainfed & 2012-2013 & Arrihane & 17 Nov. \\
\hline \multirow[t]{6}{*}{ Khemis Zemamra } & \multirow{6}{*}{$\begin{array}{l}32.633 \\
8.700\end{array}$} & Durum & Irrigated & 2011-2012 & Marzak, Karim, Tarek* & 09 Dec. \\
\hline & & Soft-low & Irrigated & 2011-2012 & Achtar, Amal* & 09 Dec. \\
\hline & & Soft-high & Irrigated & 2011-2012 & Arrihane & 09 Dec. \\
\hline & & Durum & Irrigated & 2012-2013 & Marzak*, Karim*, Tarek & 26 Nov. \\
\hline & & Soft-low & Irrigated & 2012-2013 & Achtar*, Amal & 26 Nov. \\
\hline & & Soft-high & Irrigated & $2012-2013$ & Arrihane* & 26 Nov. \\
\hline \multirow[t]{3}{*}{ Marchouch } & \multirow{3}{*}{$\begin{array}{l}33.987 \\
6.496\end{array}$} & Durum & Rainfed & 2011-2012 & Marzak, Karim, Tarek & 12 Dec. \\
\hline & & Soft-low & Rainfed & 2011-2012 & Achtar, Amal & 12 Dec. \\
\hline & & Soft-high & Rainfed & 2011-2012 & Arrihane & 12 Dec. \\
\hline
\end{tabular}

*Experimental data used to calibrate the crop models 
Fig. 2 Locations of the sites of Sidi El Aydi, Khemis Zemamra and Marchouch in which the experimental trials used to calibrate the crop models parameters were carried out. The main six Moroccan agroecological zones are redrawn from Gommes et al. 2009

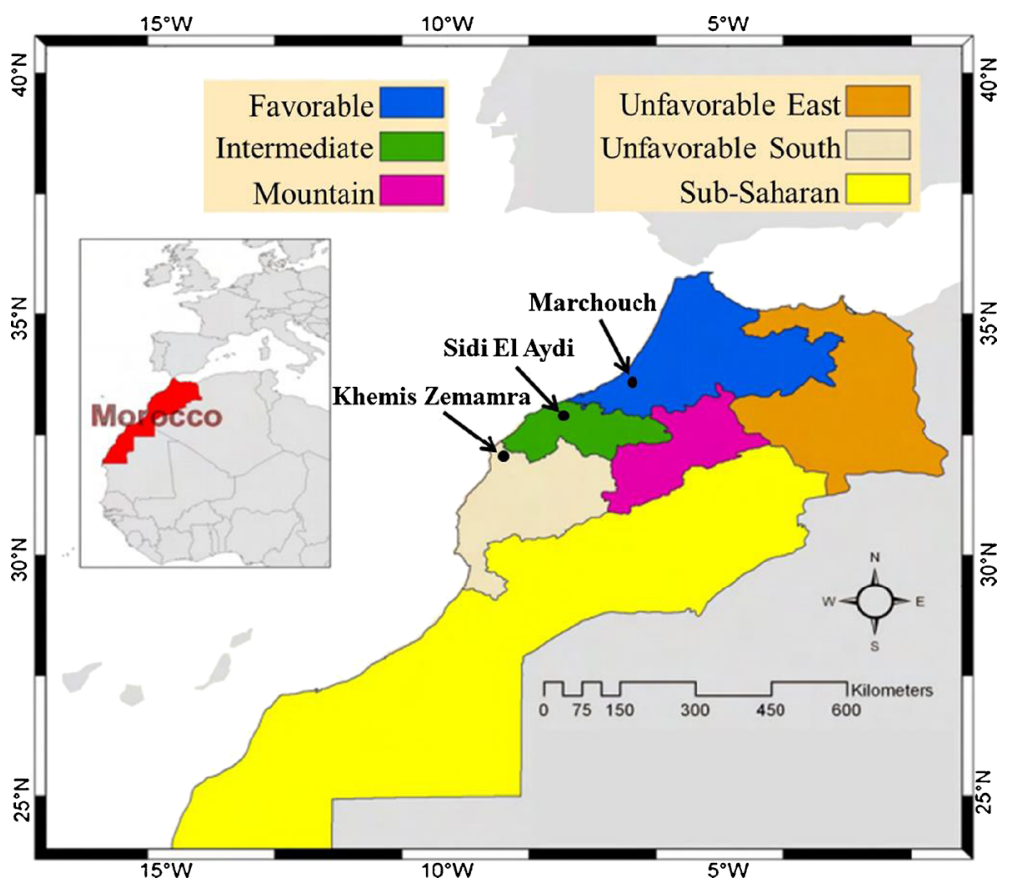

Phenological stages of emergence, code 09 of the Biologische Bundesanstalt, Bundessortenamt und CHemische Industrie (BBCH) scale for cereals (Lancashire et al. 1991), tillering (BBCH 21), stem elongation (BBCH 31), flowering (BBCH 61) and maturity $(\mathrm{BBCH} 92)$ were determined. Aboveground biomass was measured six times during the crop cycle for all the cultivars and for both irrigation treatments. After physiological maturity, samples of $1 \mathrm{~m}^{2}$ were hand-collected at ground level and used to determine aboveground biomass, harvest index, final yield and yield components.

Analysis of variance was performed using GenStat Discovery Edition 4 (VSN International, UK).

\subsection{The modelling solutions}

Two models for the simulation of crop growth and development were used in this study: WOFOST (Van Keulen and Wolf 1986, version 7.1) and CropSyst (Stöckle et al. 2003, version 3.02.23). WOFOST represents canopy architecture as divided in three horizontal layers, which intercept solar radiation by considering the direct and diffuse components of light. Leaf area index increase is estimated as a function of air temperature during early phenological stages, and later on from a development-dependent specific leaf area and the dry weight of leaves. Leaf death is computed as a function of selfshading and senescence. Three instantaneous gross $\mathrm{CO}_{2}$ assimilation rates are calculated in different moments during each day, and are used to derive daily gross photosynthesis according to the points of a Gaussian integration. Biomass accumulation is derived after accounting for maintenance and 
Table 2 Average air temperature (temp.) and cumulated rainfall (rain) for the cropping seasons (from September till May) in which the experimental trials were carried out. FAO classification - Soil type - and physical soil properties of the two experimental sites in which rainfed field trials were carried out are provided

\begin{tabular}{|c|c|c|c|c|c|c|c|c|c|c|c|c|}
\hline \multirow[t]{2}{*}{ Site } & \multirow{2}{*}{$\begin{array}{l}\text { Climatic } \\
\text { variable } \\
\text { Cropping } \\
\text { season }\end{array}$} & \multicolumn{11}{|c|}{ Soil pedological parameters } \\
\hline & & $\begin{array}{l}\text { Temp. } \\
\left({ }^{\circ} \mathrm{C}\right)\end{array}$ & $\begin{array}{l}\text { Rain } \\
(\mathrm{mm})\end{array}$ & $\begin{array}{l}\text { Depth } \\
\text { (cm) }\end{array}$ & $\begin{array}{l}\text { Sand } \\
(\%)\end{array}$ & $\begin{array}{l}\text { Clay } \\
(\%)\end{array}$ & $\begin{array}{l}\text { Silt } \\
(\%)\end{array}$ & $\begin{array}{l}\text { Soil } \\
\text { type }\end{array}$ & $\begin{array}{l}\text { Field capacity } \\
\left(\mathrm{m}^{3} \mathrm{~m}^{-3}\right)\end{array}$ & $\begin{array}{l}\text { Wilting point } \\
\left(\mathrm{m}^{3} \mathrm{~m}^{-3}\right)\end{array}$ & $\begin{array}{l}\text { Bulk density } \\
\left(\mathrm{g} \mathrm{cm}^{-3}\right)\end{array}$ & $\begin{array}{l}\text { Water } \\
\text { table (m) }\end{array}$ \\
\hline \multirow[t]{3}{*}{ Sidi El Aydi } & 2011-2012 & 21.91 & 154.4 & $0-20$ & 20.5 & 26.5 & 53 & \multirow[t]{3}{*}{ Vertisols } & 0.30 & 0.18 & 1.14 & \multirow[t]{3}{*}{70} \\
\hline & \multirow[t]{2}{*}{$2012-2013$} & \multirow[t]{2}{*}{20.23} & \multirow[t]{2}{*}{510.7} & $20-40$ & 17.5 & 36 & 46.5 & & 0.32 & 0.16 & 1.29 & \\
\hline & & & & $40-60$ & 15 & 48.5 & 36.5 & & 0.33 & 0.19 & 1.39 & \\
\hline Khemis Zemamra & $\begin{array}{l}2011-2012 \\
2012-2013\end{array}$ & $\begin{array}{l}16.42 \\
17.23\end{array}$ & $\begin{array}{l}245.0 \\
4402\end{array}$ & & \multicolumn{8}{|c|}{ No information available, simulations were performed under potential conditions } \\
\hline \multirow[t]{3}{*}{ Marchouch } & \multirow[t]{3}{*}{ 2011-2012 } & \multirow[t]{3}{*}{15.51} & \multirow[t]{3}{*}{245.2} & $0-20$ & 12.7 & 50 & 37.3 & \multirow[t]{3}{*}{ Luvisols } & 0.39 & 0.17 & 1.41 & \multirow[t]{3}{*}{$60-70$} \\
\hline & & & & $20-40$ & 10.5 & 51.3 & 38.2 & & 0.41 & 0.18 & 1.47 & \\
\hline & & & & $40-60$ & 12.4 & 52.5 & 35.1 & & 0.40 & 0.17 & 1.54 & \\
\hline
\end{tabular}

growth respiration, with a dynamic partitioning of assimilates to the different plant organs.

CropSyst has a lower level of detail in the reproduction of the biophysical processes involved with crop growth. The dynamics of leaf area index evolution are simulated as a function of aboveground biomass, of a constant specific leaf area value, and of an empirical parameter representing partitioning to leaves and stems. Leaves' death is simulated by assigning a thermal time threshold to each daily emitted leaf area units. Potential biomass accumulation is computed as the minimum between a transpiration use efficiency approach, which allows considering a reduction of biomass accumulation rate for values of vapour pressure deficit (Tanner and Sinclair 1983) and a radiation use efficiency approach. No dynamic partitioning of assimilates to the different plant organs is simulated by the model.

In order to take into account the impact of water stress during crop growth, the "tipping bucket" approach to soil water redistribution was coupled to the two crop models. This approach assumes that water can move only downward through the soil profile, filling up the layers until field capacity is reached, with the fraction of water exceeding this threshold moving to the deeper layer (Romano et al. 1998). This approach was preferred to more complex models - such as those based on solutions of the Richards' equation - since this study targets the development of large-area operational systems. Given the uncertainty in information on physical soil properties for such spatial scales is usually non negligible, we preferred to use an approach for soil water redistribution coherent with the quality of data available in large-area databases. Moreover, the need for frequent updatingi.e. re-running-operational monitoring and forecasting systems suggested to use an approach parsimonious in terms of computational cost.
Local experts' knowledge of Moroccan partners suggested discriminating among low-Achtar, Amal-and highpotential-Arrihane - soft wheat cultivars; therefore, three independent parameter sets were developed: one for durum and two for soft wheat. Parameters calibration was performed in three steps: first, parameters involved with phenology were considered, then those involved with crop growth under irrigated, i.e. potential, conditions and finally, those involved with sensitivity to water stress. Model parameters were calibrated using only observations collected in irrigated plots, whereas also data collected under rainfed conditions were used for evaluation. This avoided including factors involved with the impact of water stress into the values of parameters involved with crop growth and development under potential conditions. The few remaining model parameters modulating the response to water stress were left to the default values. The WOFOST and CropSyst parameters identified by Confalonieri et al. (2013b) as the most relevant for wheat in the country were calibrated using a trial and error procedure. For CropSyst, the parameters under calibration were biomass transpiration coefficient $\left(\mathrm{kPa} \mathrm{kg} \mathrm{m}^{-3}\right)$, maximum radiation use efficiency $\left(\mathrm{g} \mathrm{MJ}^{-1}\right)$ and optimum temperature for growth $\left({ }^{\circ} \mathrm{C}\right)$, whereas for WOFOST the calibration was performed on efficiency of conversion into storage organs $\left(\mathrm{kg} \mathrm{kg}^{-1}\right)$, maximum $\mathrm{CO}_{2}$ assimilation rate at emergence $\left(\mathrm{kg} \mathrm{ha}^{-1} \mathrm{~h}^{-1}\right)$ and assimilation reduction factor at 14 and $23{ }^{\circ} \mathrm{C}(-)$. Once the parameters were calibrated, the two models were evaluated on independent datasets (Table 1).

Calibrated parameter values are within the range of values that can be found in the literature for studies on the parameterization of CropSyst (e.g., Bechini et al. 2006) and WOFOST-type models (e.g., Richter et al. 2010) for wheat, and they are available at http://www.robertoconfalonieri.it/ TMP/ASDE/Appendices.zip. 
The agreement between measured and simulated data was quantified by using relative root mean square error (RRMSE; Jørgensen et al. 1986; minimum and optimum $=0 \%$, maximum $=+\infty \%$ ); modelling efficiency (EF; Nash and Sutcliffe 1970; from $-\infty$ to 1 , optimum $=1$ ), coefficient of residual mass (CRM; Loague and Green 1991; optimum=0, if positive indicates model underestimation), and coefficient of determination $\left(R^{2}\right)$.

\subsection{Large-area application of the two modelling solutions}

The two modelling solutions including the crop models WOFOST and CropSyst and the soil hydrological model were implemented using a component-based approach, with each component referring to a specific biophysical domain. The crop models were thus implemented in the CropML library (http://agsys.cra-cin.it/tools/cropml/help/), whereas the model for soil hydrology was implemented in the SoilW component (http://agsys.cra-cin.it/tools/soilw/help/). The solutions were then run under the BioMA platform (Biophysical Model Applications; http://agsys.cra-cin.it/tools/bioma/help/). The methodology adopted in this study to perform spatially distributed simulations was based on independent runs for each of the $25 \times 25-\mathrm{km}$ elementary simulation units derived from the European Commission interpolated grid weather (EC-JRC MARS database, Micale and Genovese 2004). Soil and management data at the same spatial resolution were derived from the same database, with soil properties corresponding to the most represented soil typological unit within each grid cell.

Weather data within the period 2000-2012 were analysed to identify two seasons contrasting for pluviometric and thermal regimes, in order to analyse crop models' response under a wide range of weather conditions. Two cropping seasons were thus selected because of their different amount of cumulated rainfall during the wheat growing period, i.e. from December to June: the 2009-2010 cropping season presented an average amount of rainfall of $490.8 \mathrm{~mm}$ and an average air temperature of $16.2{ }^{\circ} \mathrm{C}$, whereas the cumulated precipitation in the 2011-2012 cropping season was $130.6 \mathrm{~mm}$, with an average air temperature of $15.2{ }^{\circ} \mathrm{C}$. Spatially distributed results are presented as simulated aboveground biomass at physiological maturity, given that it is the culmination of many processes related to crop growth and development, thus being strongly related to actual yield. Further, this variable is usually used as early predictor in crop yield forecasting systems as it evolves during the whole crop cycle (Bastiaanssen and Ali 2003). Crop models outputs were then compared to the official yields provided by the Moroccan Ministry of Agriculture, in order to evaluate the coherence of models predictions.

\section{Results and discussion}

\subsection{Experimental results and model evaluation at field level}

Figure 3 presents, as an example, aboveground biomass data collected at Sidi El Aydi; blue and red circles refer, respectively, to irrigated and rainfed plots. For soft wheat, results are presented separately for low- and high-potential cultivars, represented by Amal and Achtar, and by Arrihane, respectively. Error bars represent the variability among cultivars.

The differences due to the irrigation treatment were statistically significant $(p<0.05)$ for most of the combination site $\times$ season and for most sampling events. The few exceptions, e.g. soft wheat in 2012-2013 at Sidi El Aydi, were due to particular conditions occurred during the season, i.e. rainfall above the average. Differences among varieties were often significant, with the cultivar Arrihane fully demonstrating its higher potential compared to the others.

Figure 3 also shows the comparison between measured aboveground biomass data and daily values for the same variable simulated with WOFOST and CropSyst: the linesblue for irrigated and red for rainfed plots - correspond to the daily mean of the data simulated with the two models; the coloured shades around the lines indicate the standard deviation of the models' outputs. Field data were correctly reproduced by both the models, although their level of accuracy varied during the season. Both WOFOST and CropSyst properly reproduced the observed gap between irrigated and rainfed treatments, that was larger in the season 2011-2012 compared to the one observed in 2012-2013 because of the lower rainfall amounts. Indeed, simulated aboveground biomass values simulated for irrigated and rainfed plots were similar for the season 2012-2013, especially for Arrihane. A large standard deviation between the outputs of the two models can be observed for the 2011-2012 simulations performed for durum wheat cultivars under rainfed conditions, whereas - in other cases - the differences between the values simulated by the two models were decidedly less pronounced. The satisfactory performances achieved by both the models are confirmed by the values of the agreement metrics presented in Table 3.

Both the models succeeded in correctly reproducing the observed phenological development for the calibration and evaluation datasets, regardless of the experimental site, treatment and season. $R^{2}$ values between observed and simulated Julian days corresponding to the phenological stages were, indeed, always higher than 0.95 , with RRMSE ranging between 4.32 and $6.50 \%$. The agreement metrics calculated on aboveground biomass data highlighted the greater ability of both the models in reproducing the time trend observed for the soft wheat high-potential cultivar. CropSyst achieved the best values of modelling efficiency for irrigated conditions, whereas WOFOST was the model that overall showed the highest 
Fig. 3 Measured and simulated aboveground biomass observed in Sidi El Aydi during the cropping seasons 2011-2012 and 2012-2013. The average values simulated by WOFOST and CropSyst are reported in blue for irrigated trials and in red for rainfed trials. The coloured shades besides the curves indicate the daily standard deviation of the outputs of the two models. The points and their error bars correspond to the samplings of aboveground biomass of the wheat varieties tested. Both the models correctly reproduced the large gap between aboveground biomass observed for the irrigated and rainfed trials in the 20112012 season. The analysis of the standard deviations between models outputs highlighted the overall similarity in the models predictions
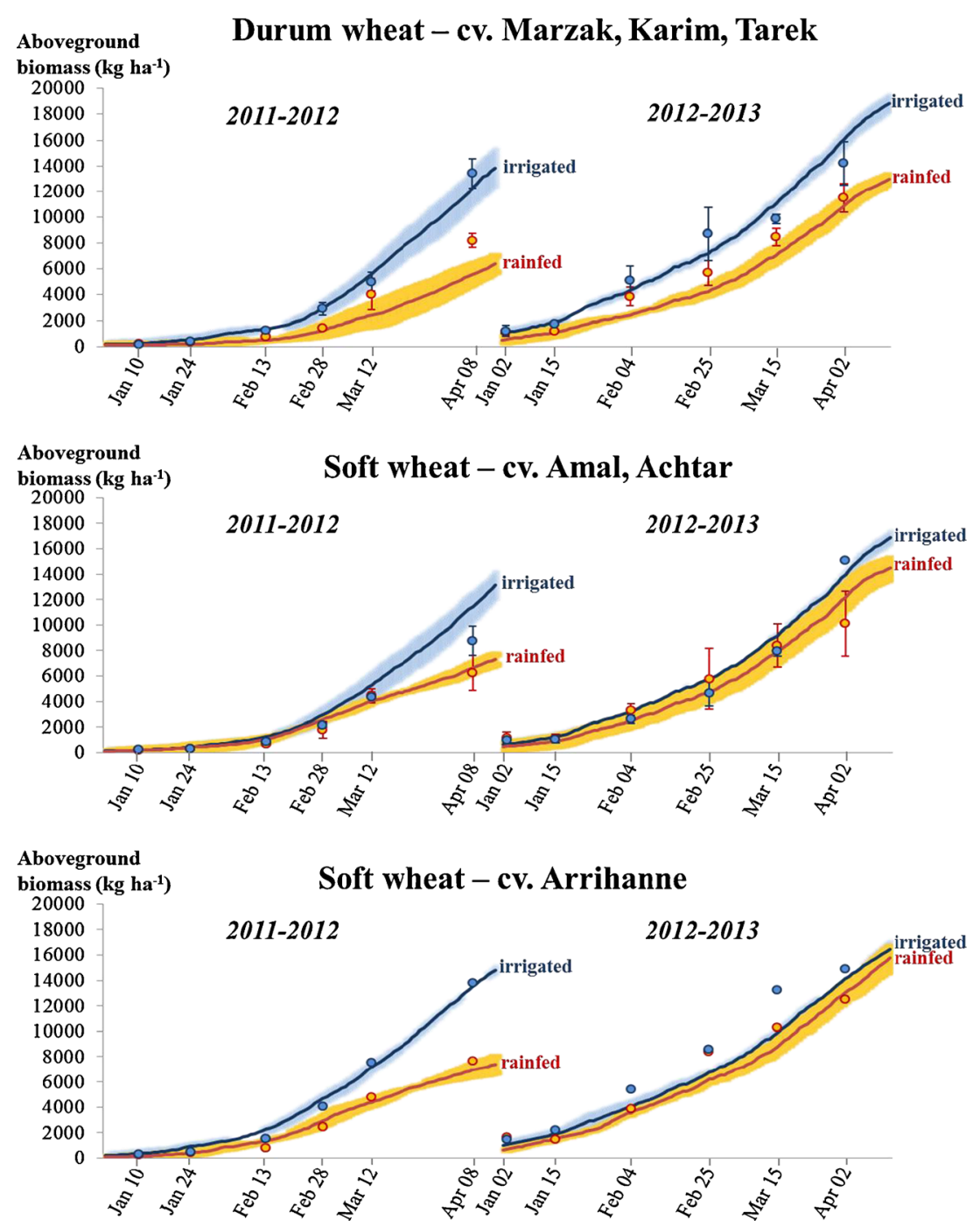

accuracy, with average RRMSE of $29.40 \%$. The simulations carried out for the other groups of cultivars (soft-low potential and durum) denoted slight worse performances, with WOFOST achieving again the best results, especially for rainfed conditions. The values of the coefficient of residual mass indicated the absence of systematic under- or overestimating behaviours, and the $R^{2}$ values - always higher than 0.91 - confirmed the satisfactory performance in reproducing observations throughout the season.

In general, the performances of the two models are in line with those discussed in comparable modelling studies where simulated aboveground biomass was tested against field observations (e.g., Bouman and Van Laar 2006; Thorp et al. 2010). Despite its lower complexity, CropSyst performed similarly to WOFOST. The main reason for the slight differences in the data simulated by the two models under irrigated conditions is due to the CropSyst tendency to overestimate biomass accumulation rates during early stages. During the season 2011-
2012, indeed, wheat was negatively affected by severe drought conditions during December 2011 and February-March 2012, and WOFOST better estimated the impact of water stress. This could indicate a higher robustness of WOFOST in case of water-limiting conditions, contrarily to what was observed for paddy rice simulations by Confalonieri et al. (2010), who reported that this model presented a larger variability in accuracy when applied to different agro-meteorological contexts. Further improvements of the models response to drought could be achieved by simulating the impact of insufficient water availability on wheat phenological development (Szulczewski et al. 2012).

The calibration, performed using data collected in dedicated field experiments, allowed adapting WOFOST and CropSyst to the conditions explored by local wheat cultivars in Morocco, and demonstrated an overall homogeneity in the models responses to the main agroenvironmental drivers. 
Table 3 Evaluation metrics computed for WOFOST and CropSyst

\begin{tabular}{|c|c|c|c|c|c|c|c|}
\hline Wheat & Process & Activity & Model & RRMSE & $\mathrm{EF}$ & CRM & $R^{2}$ (slope) \\
\hline \multirow[t]{12}{*}{ Durum } & \multirow[t]{6}{*}{ Development } & \multirow[t]{2}{*}{ Calibration } & WOFOST & 10.24 & 0.97 & 0.00 & $0.97(1.01)$ \\
\hline & & & CropSyst & 10.48 & 0.97 & 0.00 & $0.97(1.01)$ \\
\hline & & \multirow[t]{4}{*}{ Validation } & \multirow[t]{2}{*}{ WOFOST } & 13.26 & 0.95 & 0.01 & $0.95(1.01)$ \\
\hline & & & & 7.95 & 0.98 & -0.03 & $0.99(1.06)$ \\
\hline & & & \multirow[t]{2}{*}{ CropSyst } & 14.07 & 0.96 & 0.00 & $0.96(1.01)$ \\
\hline & & & & 8.08 & 0.98 & -0.03 & $0.99(1.06)$ \\
\hline & \multirow[t]{6}{*}{ Growth } & \multirow[t]{2}{*}{ Calibration } & WOFOST & 42.93 & 0.76 & 0.02 & $0.96(1.21)$ \\
\hline & & & CropSyst & 39.47 & 0.71 & -0.18 & $0.95(0.87)$ \\
\hline & & \multirow[t]{4}{*}{ Validation } & \multirow[t]{2}{*}{ WOFOST } & 48.34 & 0.72 & 0.11 & $0.94(1.41)$ \\
\hline & & & & 42.53 & 0.81 & 0.14 & $0.94(1.40)$ \\
\hline & & & \multirow[t]{2}{*}{ CropSyst } & 40.97 & 0.73 & -0.03 & $0.94(1.06)$ \\
\hline & & & & 65.83 & 0.48 & -0.45 & $0.93(0.76)$ \\
\hline \multirow[t]{12}{*}{ Soft-low } & \multirow[t]{6}{*}{ Development } & \multirow[t]{2}{*}{ Calibration } & WOFOST & 5.49 & 0.99 & 0.01 & $0.99(0.69)$ \\
\hline & & & CropSyst & 5.81 & 0.99 & 0.01 & $0.99(1.27)$ \\
\hline & & \multirow[t]{4}{*}{ Validation } & \multirow[t]{2}{*}{ WOFOST } & 6.17 & 0.99 & 0.01 & $0.99(0.69)$ \\
\hline & & & & 6.56 & 0.99 & -0.02 & $0.99(1.04)$ \\
\hline & & & \multirow[t]{2}{*}{ CropSyst } & 6.38 & 0.99 & 0.01 & $0.99(1.27)$ \\
\hline & & & & 6.50 & 0.99 & -0.01 & $0.99(1.01)$ \\
\hline & \multirow[t]{6}{*}{ Growth } & \multirow[t]{2}{*}{ Calibration } & WOFOST & 31.23 & 0.85 & -0.06 & $0.96(0.66)$ \\
\hline & & & CropSyst & 69.79 & 0.01 & -0.49 & $0.98(0.96)$ \\
\hline & & \multirow[t]{4}{*}{ Validation } & \multirow[t]{2}{*}{ WOFOST } & 48.97 & 0.37 & -0.14 & $0.97(0.88)$ \\
\hline & & & & 46.07 & 0.73 & 0.17 & $0.91(1.38)$ \\
\hline & & & \multirow[t]{2}{*}{ CropSyst } & 51.77 & 0.61 & -0.22 & $0.97(1.03)$ \\
\hline & & & & 60.80 & 0.64 & -0.37 & $0.93(0.97)$ \\
\hline \multirow[t]{12}{*}{ Soft-high } & \multirow[t]{6}{*}{ Development } & \multirow[t]{2}{*}{ Calibration } & WOFOST & 3.84 & 1.00 & 0.00 & $1.00(1.00)$ \\
\hline & & & CropSyst & 5.52 & 0.99 & -0.01 & $0.99(1.00)$ \\
\hline & & \multirow[t]{4}{*}{ Validation } & \multirow[t]{2}{*}{ WOFOST } & 4.80 & 0.99 & 0.04 & $1.00(1.00)$ \\
\hline & & & & 8.25 & 0.98 & -0.01 & $0.98(1.04)$ \\
\hline & & & CropSyst & 6.50 & 0.99 & 0.06 & $1.00(1.00)$ \\
\hline & & & & 8.43 & 0.98 & -0.01 & $0.98(1.01)$ \\
\hline & Growth & Calibration & WOFOST & 33.59 & 0.77 & 0.26 & $0.98(1.25)$ \\
\hline & & & CropSyst & 35.61 & 0.79 & -0.09 & $0.98(1.08)$ \\
\hline & & Validation & WOFOST & 25.23 & 0.89 & 0.15 & $0.96(1.16)$ \\
\hline & & & & 21.35 & 0.93 & 0.08 & $0.96(1.08)$ \\
\hline & & & CropSyst & 24.48 & 0.90 & -0.14 & $0.96(1.02)$ \\
\hline & & & & 40.46 & 0.69 & -0.22 & $0.95(0.75)$ \\
\hline
\end{tabular}

Coefficients of determination were significant at the $95 \%$ confidence level

Evaluated metrics for irrigated conditions are in normal font and evaluated metrics for rainfed conditions are in italics

Development refers to metrics computed on the observed and simulated days of the season corresponding to the phenological stages of emergence, tillering, stem elongation, flowering and maturity; Growth refers to metrics computed on the measured and the simulated aboveground biomass values $R R M S E$ relative root mean square error (Jørgensen et al. 1986), EF modelling efficiency (Nash and Sutcliffe 1970), CRM coefficient of residual mass (Loague and Green 1991)

\subsection{Large-area simulations}

Figure 4 presents aboveground biomass values simulated by WOFOST and CropSyst under water-limiting conditions for the 2009-2010 and 2011-2012 cropping seasons for the whole Moroccan wheat-cropped area. Data simulated using the parameter set calibrated for soft wheat high-potential cultivars are not shown since presented intermediate results.

In order to evaluate the coherence of models projections, large-area simulation results were compared with official yield statistics $\left(\mathrm{t} \mathrm{ha}^{-1}\right)$ for the four main wheat-cropped regions of Morocco (NUTS 1 classification: centre, centre north, north 
west and Tensift, source Moroccan Ministry of Agriculture). The two models succeeded in reproducing higher productions in the 2009-2010 cropping season (Fig. 4b, f for CropSyst, Fig. 4d, h for WOFOST) with respect to those simulated for 2011-2012 (Fig. 4a, e for CropSyst, Fig. 4c, g for WOFOST). Official yields were, indeed, decidedly higher in 2009-2010 for both durum, i.e. 1.76 versus $1.04 \mathrm{t} \mathrm{ha}^{-1}$ and soft, i.e. 1.72 versus $1.16 \mathrm{t} \mathrm{ha}^{-1}$ wheat. Moreover, in 2011-2012, both models agreed with official statistics in simulating a negative north-south gradient of aboveground biomass, with the highest production in north-west region-official yields: 1.61 and $1.51 \mathrm{t} \mathrm{ha}^{-1}$ for durum and soft wheat, respectively - and lowest production in the southern Tensift regionofficial yields: 0.94 and $0.84 \mathrm{t} \mathrm{ha}^{-1}$ for durum and soft wheat, respectively. Conversely, in 2009-2010, CropSyst appeared as the only model capable to reproduce the gradient present in
Fig. 4 CropSyst and WOFOST simulations of the aboveground biomass of durum and soft wheat - low productivity — on the whole agricultural areas of Morocco in the cropping seasons 2009-2010 and 2011-2012. The maps show the simulation of lower biomass values for the cropping season 2011-2012, characterised by unfavourable rainfall amount and distribution. In general, the values of aboveground biomass simulated by WOFOST are higher than those simulated by CropSyst. The analysis of the spatial patterns simulated by the two models underlined relevant differences across the Moroccan agricultural regions, despite their homogeneity in reproducing data from field experiments

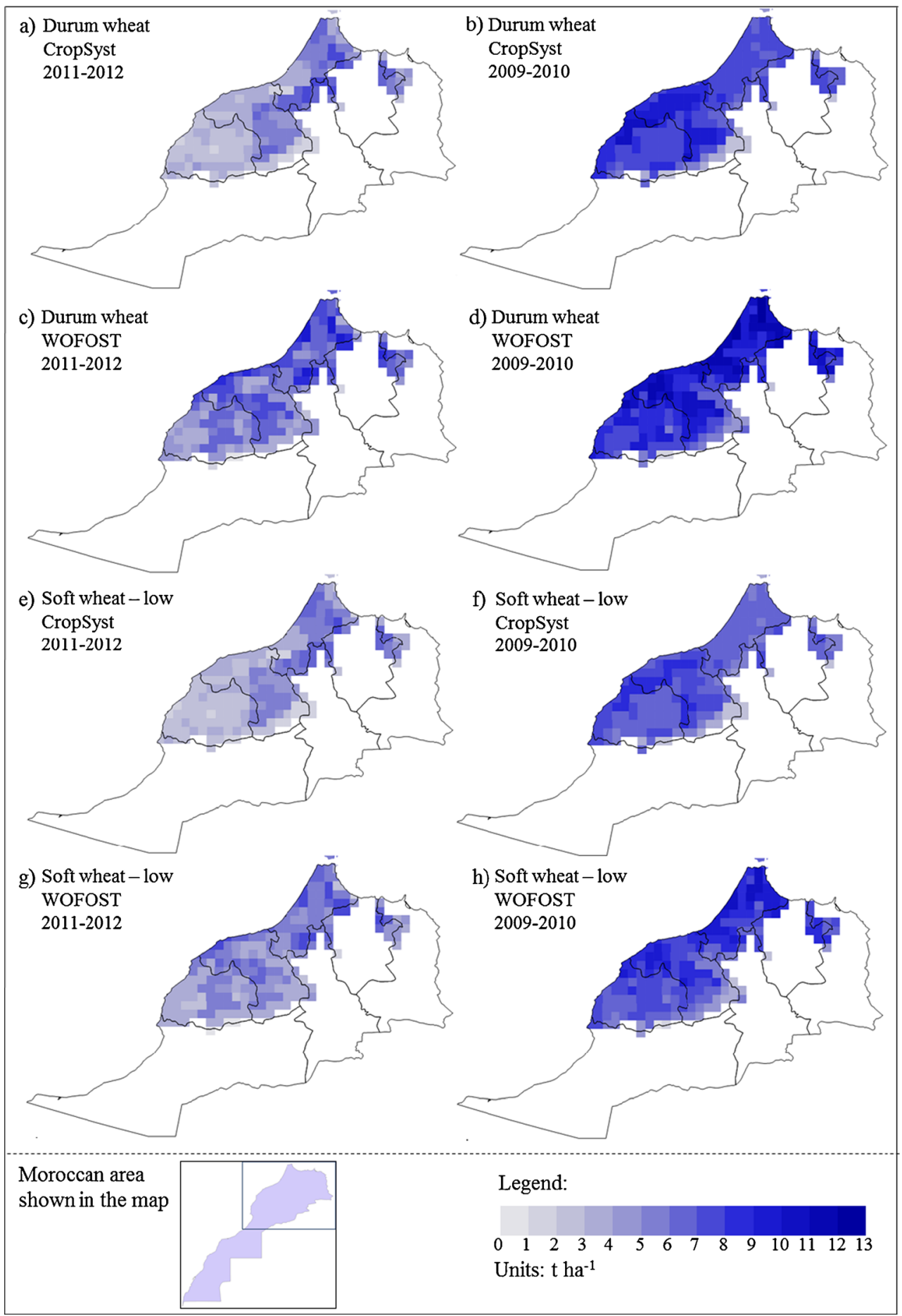


official yields, simulating higher production levels in the central and Tensift regions (official yields: 1.84 and $2.06 \mathrm{tha}^{-1}$, respectively), whereas WOFOST simulated homogenous production levels throughout the whole Moroccan wheat-cropped area. The analysis of the percentage differences in regional official yields between 2009-2010 and 2011-2012 resulted in a high correlation $-R^{2}=0.87-$ in soft and durum wheat yield gaps. The reason for the good CropSyst performances is likely related to the transpiration use efficiency approach used by CropSyst for net photosynthesis: this approach, in fact, explicitly accounts for the impact of vapour pressure deficit on photosynthesis, with vapour pressure deficit playing a key role in affecting crops productivity in arid environments (Gourdji et al. 2012).

Contrarily to what was discussed for the performances of the two models while reproducing data from field experiments, the results of the spatially distributed simulations highlighted clear differences in the aboveground biomass data simulated by the two models. However, the overall coherence between simulated and official yields supports the use of WOFOST and CropSyst as operational tools for wheat monitoring and forecasting in the country.

\section{Conclusion}

In this study, we demonstrated that a proper parameterization of CropSyst and WOFOST allowed both the models to reproduce phenological development of durum and soft wheat Moroccan varieties, as well as the impact of drought on biomass accumulation in two seasons contrasting for rainfall amounts and distribution. The performances of the models outlined an adequate reproduction of the gap between aboveground biomass values simulated for drip irrigated and the rainfed plots under the dry conditions that characterised the 2011-2012 season, whereas - in the wet 2012-2013 seasonboth the models simulated similar values for the two treatments. The spatially distributed application of the models confirmed their ability in differentiating the response to different degrees of drought. Despite the similar performances shown by the two models during field-level calibration and evaluation, their application to the whole Moroccan wheatcropped area highlighted the different behaviour of the two models when applied to seasons differing for the degree of drought, because of the different approaches used to reproduce key processes involved with wheat growth. Hence, this work encourages the implementation of CropSyst and WOFOST in multi-model, operational crop yield forecasting systems capable of reproducing the impact of drought in the semi-arid regions. Once operational, such system would provide an effective support to Moroccan stakeholders, via timely wheat production forecasts able to properly manage policies aimed at satisfying internal demand.
Acknowledgments This study has been partially funded under the EU FP7 collaborative project, Grant Agreement No. 270351, Crop monitoring as an E-agriculture tool in developing countries (E-Agri).

\section{References}

Asseng S, Ewert F, Rosenzweig C et al (2013) Quantifying uncertainties in simulating wheat yields under climate change. Nat Clim Chang 3: 827-832. doi:10.1038/nclimate1916

Balaghi R, Tychon B, Eerens H, Jilbene M (2008) Empirical regression models using NDVI, rainfall and temperature data for the early prediction of wheat grain yields in Morocco. Int J Appl Earth Obs 10:438-452. doi:10.1016/j.jag.2006.12.001

Balaghi R, Jlibene M, Tychon B, Eerens H (2012) La prédiction agrométéorologique des rendements céréaliers au Maroc. INRA, Maroc

Basso B, Cammarano D, Carfagna E (2013) Review of crop yield forecasting methods and early warning systems. Food and Agriculture Organization. http://www.fao.org/fileadmin/templates/ ess/documents/meetings_and_workshops/GS_SAC_2013/ Improving methods for_crops_estimates/Crop_Yield Forecasting_Methods_and_Early_Warning_Systems_Lit_review. pdf. Accessed $14 \mathrm{Feb} 2014$

Bastiaanssen WGM, Ali S (2003) A new crop yield forecasting model based on satellite measurements applied across the Indus Basin, Pakistan. Agric Ecosyst Environ 94:321-340. doi:10.1016/S01678809(02)00034-8

Bechini L, Bocchi S, Maggiore T, Confalonieri R (2006) Parameterization of a crop growth and development simulation model at sub-model components level. An example for winter wheat (Triticum aestivum L.). Environ Model Softw 21:1024-1054. doi: 10.1016/j.envsoft.2005.05.006

Bouftass F, Labhilili M, Ezzahiri B, Ziouti A (2010) Molecular polymorphism of the wheat leaf rust fungus in Morocco using amplified fragment length polymorphism. Phytopathology 158:111-116. doi: 10.1111/j.1439-0434.2009.01573.x

Bouman BAM, Van Laar HH (2006) Description and evaluation of the rice growth model ORYZA2000 under nitrogen-limited conditions. Agric Syst 87:249-273. doi:10.1016/j.agsy.2004.09.011

Confalonieri R, Bregaglio S, Acutis M (2010) A proposal of an indicator for quantifying model robustness based on the relationship between variability of errors and of explored conditions. Ecol Model 221: 960-964. doi:10.1016/j.ecolmodel.2009.12.003

Confalonieri R, Francone C, Cappelli G, Stella T, Frasso N, Carpani M, Bregaglio S, Acutis M, Tubiello FN, Fernandes E (2013a) A multiapproach software library for estimating crop suitability to environment. Comput Electron Agric 90:170-175. doi:10.1016/j.compag. 2012.09.016

Confalonieri R, Bregaglio S, Cappelli G, Francone C, Carpani M, Acutis M, El Aydam M, Niemeyer S, Balaghi R, Dong Q (2013b) Wheat modelling in Morocco unexpectedly reveals predominance of photosynthesis versus leaf area expansion plant traits. Agron Sustain Dev 33:393-403. doi:10.1007/s13593-012-0104-y

Duchemin B, Maisongrande P, Boulet G, Benhadj I (2008) A simple algorithm for yield estimates: evaluation for semiarid irrigated winter wheat monitored with green leaf area index. Environ Model Softw 23:876-892. doi:10.1016/j. envsoft.2007.10.003

El Bouhssini M, Ogbonnaya FC, Chen M, Lhaloui S, Rihawi F, Dabbous A (2013) Sources of resistance in primary synthetic hexaploid wheat (Triticum aestivum L.) to insect pests: Hessian fly, Russian wheat aphid and Sunn pest in the fertile crescent. Genet Resour Crop Evol 60:121-127. doi:10.1007/s10722-012-9861-3 
Gommes R, El Hairech T, Rosillon D, Balaghi R (2009) Impact of climate change on agricultural yields in Morocco. World Bank - Morocco study on the impact of climate change on the agricultural sector. Food and Agriculture Organization of the United Nations (FAO). Roma, Italy. http://www.fao.org/nr/climpag/pub/FAO_WorldBank Study_CC_Morocco_2008.pdf. Accessed 14 Feb 2014

Gourdji SM, Mthews KL, Reynolds M, Crossa J, Lobell DB (2012) An assessment of wheat yield sensitivity and breeding gains in hot environments. Proc R Soc B 20122190. doi:10.1098/rspb.2012.2190

Hertel TW, Martin W, Leister AM (2010) Potential implications of a special safeguard mechanism in the world trade organization: the case of wheat. World Bank Econ Rev 24:330-359. doi:10.1093/ wber/lhq010\%U

Institute National de la Recherche Agronomique (INRA) (2002) Caractérisation du climat et stratégies de lutte contre les effets de la sécheresse au Maroc. Note interne pour le Ministère de l'Agriculture. Département d'Agronomie, INRA, Morocco

Jørgensen SE, Kamp-Nielsen L, Christensen T, Windolf-Nielsen J, Westergaard B (1986) Validation of a prognosis based upon a eutrophication model. Ecol Model 32:165-182. doi:10.1016/03043800(86)90024-4

Karrou M (1998) Observations on effect of seeding pattern on water-use efficiency of durum wheat in semi-arid areas of Morocco. Field Crop Res 59:175-179. doi:10.1016/S0378-4290(98)00118-X

Lancashire PD, Bleiholder H, Langelüddecke P, Stauss R, Van den Boom T, Weber E, Witzenberger A (1991) An uniform decimal code for growth stages of crops and weeds. Ann Appl Biol 119:561-601. doi: 10.1111/j.1744-7348.1991.tb04895.x

Loague K, Green RE (1991) Statistical and graphical methods for evaluating solute transport models: overview and application. J Contam Hydrol 7:51-73. doi:10.1016/0169-7722(91)90038-3

Micale F, Genovese G (2004) Methodology of the MARS crop yield forecasting system. Meteorological data collection, processing and analysis. European Communities, Italy
Mrabet R (2000) Differential response of wheat to tillage management systems in a semiarid area of Morocco. Field Crop Res 66:165-174. doi:10.1016/S0378-4290(00)00074-5

Nash JE, Sutcliffe JV (1970) River flow forecasting through conceptual models, part I - a discussion of principles. J Hydrol 10:282-290. doi:10.1016/0022-1694(70)90255-6

Porter JR, Semenov MA (2005) Crop responses to climatic variation. Philos Trans R Soc B 360:2021-2035. doi:10.1098/rstb. 2005.1752

Richter GM, Acutis M, Trevisiol P, Latiri K, Confalonieri R (2010) Sensitivity analysis for a complex crop model applied to durum wheat in the Mediterranean. Eur J Agron 32:127-136. doi:10. 1016/j.eja.2009.09.002

Romano N, Brunone B, Santini A (1998) Numerical analysis of onedimensional unsaturated flow in layered soils. Adv Water Resour 21:315-324. doi:10.1016/S0309-1708(96)00059-0

Stöckle CO, Donatelli M, Nelson R (2003) CropSyst, a cropping systems simulation model. Eur J Agron 18:289-307. doi:10.1016/S11610301(02)00109-0

Szulczewski W, Zyromsky A, Biniak-Pieróg M (2012) New approach in modeling spring wheat yielding based on dry periods. Agric Water Manag 103:105-113. doi:10.1016/j. agwat.2011.10.023

Tanner CB, Sinclair TR (1983) Efficient water use in crop production: research or re-search? In: Taylor HM, Jordan WR, Sinclair TR (ed) Limitations to efficient water use in crop production. Amer Soc Agron, Madison, WI, pp 1-27

Thorp KR, Hunsaker DJ, French AN, White JW, Clarke TR, Pinter PJ Jr (2010) Evaluation of the CSM-CROPSIM-CERES-wheat model as a tool for crop water management. Trans ASABE 53:87-102. doi: $10.13031 / 2013.29505$

Van Keulen H, Wolf J (1986) Modelling of agricultural production: weather soils and crops. Simulation monographs. Pudoc, Wageningen, The Netherlands 